\title{
Electric Mini - Challenges and Solutions for the electrical powertrain
}

\author{
Bruno Brito $^{1}$, Luís Tagaio ${ }^{1,}$, Pedro Matos ${ }^{1}$ Carlos Ferreira $^{1,2}$; Hugo Ribeiro ${ }^{1,2}$ \\ ${ }^{1}$ Department of Electric Engineering, E.S.T.T., Polytechnic Institute of Tomar \\ Quinta do Contador - Estrada da Serra, 2300 Tomar, Portugal, phone +351249328150, fax:+351249328187 Email: \\ blmbrito@portugalmail.pt \\ ${ }^{2}$ Instituto de Telecomunicações, Av. Rovisco Pais 1, 1049 - 001 Lisboa, Portugal \\ Phone +351-218418455, Fax: +351-218418472
}

\begin{abstract}
This paper focuses the development of an electric vehicle (EV) from the chassis of a Mini 1000. The vehicle uses two permanent magnets electrical machines coupled to the front wheels to achieve traction. The variation of the motors speed is allowed by two power electronic DC/DC converters connected to the batteries. Due to the high currents evolved there were several implementation problems. The solutions encountered are explained in this paper. Safety vehicle operation was an important issue to be achieved.
\end{abstract}

\section{Key words}

Electric Vehicle, Electronic, Power Electronics, Powertrain.

\section{Introduction}

One of the priorities of the current society is to find energetic alternatives face to fossil fuels. The unmeasured increase of those fuels consumption is not only a large environmental problem but also an energy dependence problem. During the last years the electric vehicles have demonstrated a large interest, has a new solution for the road transportation system. The EV has electric machines that are responsible for the traction and need to be powered by an electric source of energy such as batteries or fuel-cells. The objective of this project is to create a battery electric vehicle. This work involves a mechanical part and an electric/electronic one.

Along this paper several aspects are analyzed: the mechanical transmission and their adaptation to the structures; the coupling of the two electric machines on the front wheels and the design, test and optimization of two electronic DC/DC power converters. The safety of the system is of special attention and consequently several protection circuits are produced.

\section{Mechanical Dimensioning}

\section{A. Referential}

The referential of the vehicle $\left\{\mathrm{X}_{\mathrm{V}}, \mathrm{Y}_{\mathrm{V}}, \mathrm{Z}_{\mathrm{V}}\right\}$ is represented on the Fig. 1. The $x x$ 's axis is aligned with the longitudinal direction of vehicle structure $\left(\mathrm{X}_{\mathrm{V}}\right)$, the $y y$ 's point to right side $\left(\mathrm{Y}_{\mathrm{V}}\right)$ and the $z z$ 's corresponds to the vertical direction $\left(\mathrm{Z}_{\mathrm{V}}\right)$, according to the Society of Automotive Engineers (SAE) nomenclature.

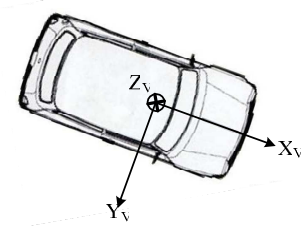

Fig. 1. Referential of the vehicle.

The origin of the vehicle referential is on the vehicle center of mass, obtained in the next section. [1] [2]

\section{B. Calculation of the center of mass (CM)}

Considering the mass of the several elements of the vehicle (batteries, wheels, electric machines, etc.) and their relative localization (Fig. 2), the $\mathrm{CM}$ is calculated using the equation (1).

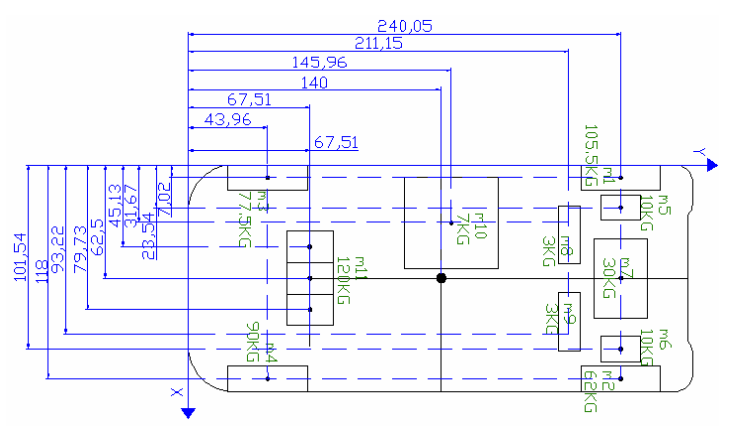

Fig. 2. Distribution of mass elements on the vehicle.

$x_{C M}=\frac{\sum_{i=1}^{n}\left(m_{i} \cdot x_{i}\right)}{\sum_{i=1}^{n} m_{i}} \quad y_{C M}=\frac{\sum_{i=1}^{n}\left(m_{i} \cdot y_{i}\right)}{\sum_{i=1}^{n} m_{i}}$

For the vehicle stability a good distribution of the weight is necessary. 


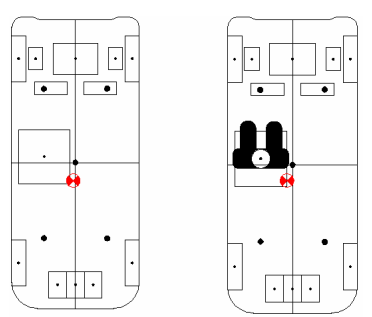

Fig. 3. Center of mass without and with pilot.

Fig. 3 Fig. 3 shows the position of center of mass on the vehicle, without pilot and whit pilot.

\section{Equation of the movement}

Considering the external forces applied to the vehicle, $F_{\text {external }}$, the vehicle mass, $m$, and acceleration, $a$, the application of Newton's second law results:

$$
\sum F_{\text {external }}=m \cdot a
$$

External forces are composed by traction forces, $F_{T}$, and the resistant forces to the movement, $F_{R T}$.

\section{1) Resistant forces}

The total resistance force to movement, $F_{R T}$ is composed by all the resistant forces presented on the vehicle:

$$
F_{R T}=F_{R R}+F_{D A}+F_{I}
$$

Where:

$F_{R R}=\left(F_{R R F}+F_{R R T}\right)-$ Rolling resistant force

$F_{R R F}-$ Rolling resistant force at front wheels

$F_{R R T}$ - Rolling resistant force at back wheels

$F_{D A}-$ Aerodynamics resistant force

$F_{I}-$ Inclination force

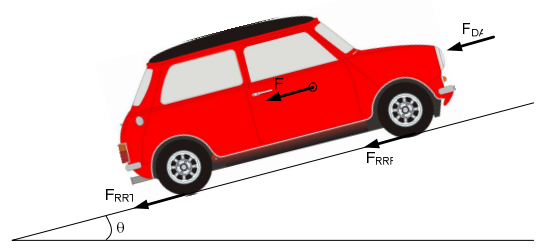

Fig. 4. Resistant forces applied on the vehicle.

At low velocities the rolling resistance force, $F_{R R}$, is the principal opposition to the movement. At higher velocities the aerodynamics resistant force, $F_{D A}$, becomes the most important one. The inclination force, $F_{I}$, is independent of the vehicle velocity.

\section{1) Inclination force}

The inclination force, $F_{I}$, depends of the vehicle mass, the acceleration due to gravity $(g)$ and of the climbing angle $(\theta)$.

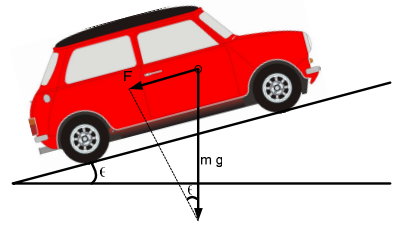

Fig. 5. Inclination force.

$$
F_{I}=m \cdot g \cdot \operatorname{sen} \theta
$$

When the vehicle is climbing this force is positive $(\theta>0)$ and when it is descent is negative $(\theta<0)$.

\section{2) Rolling resistant force}

The rolling resistant force, $F_{R R}$, is originated essentially by the tire deformation at the contact with the road and can be expressed by the equation (5):

$$
F_{R R}=f_{r} \cdot m \cdot g
$$

Where:

$$
\begin{aligned}
& f_{r} \text { - Coefficient of rolling resistance } \\
& m \text { - Mass of the vehicle }
\end{aligned}
$$

Table I. - Rolling resistant coefficient [3]

\begin{tabular}{|l|c|}
\hline \hline \multicolumn{1}{|c|}{ Road type } & $\mathrm{f}_{\mathrm{r}}$ \\
\hline \hline Concrete & $0.008-0.01$ \\
\hline Asphalt & $0.01-0.015$ \\
\hline Causeway & $0.033-0.055$ \\
\hline Snow & $0.025-0.037$ \\
\hline Sand & $0.15-0.3$ \\
\hline
\end{tabular}

\section{3) Aerodynamics resistant force}

The aerodynamic forces produced on a vehicle arise from drag and viscous friction. Because the air flow over a vehicle is very complex, it is necessary to develop semi-empirical models to represent the effect. Therefore the aerodynamic drag is characterized by the following equation [4]:

$$
F_{D A}=\frac{1}{2} \cdot \rho \cdot C_{D} \cdot A_{f} \cdot V_{V}^{2}
$$

Where:

$$
\begin{aligned}
& \rho \text { - Air density } \\
& C_{D} \text { - Aerodynamic drag coefficient } \\
& A_{f} \text { - Frontal area of the vehicle } \\
& V_{V}-\text { Velocity of the vehicle } \\
& \text { 1.4) Estimation of } F_{R R} \text { and } F_{D A} \text { through } \\
& \text { experimental tests. }
\end{aligned}
$$

The climbing or descent force $F_{I}$, is easily estimated because depends directly on the vehicle mass and on the climbing angle (variables that are easily obtained). The rolling resistance and the aerodynamic drag coefficients can be obtained with experimental tests to the vehicle in 
a flat ground $\left(F_{I}=0\right)$ and at several different velocities. Those tests were performed at Lago Azul aerodrome illustrated in Fig. 6.
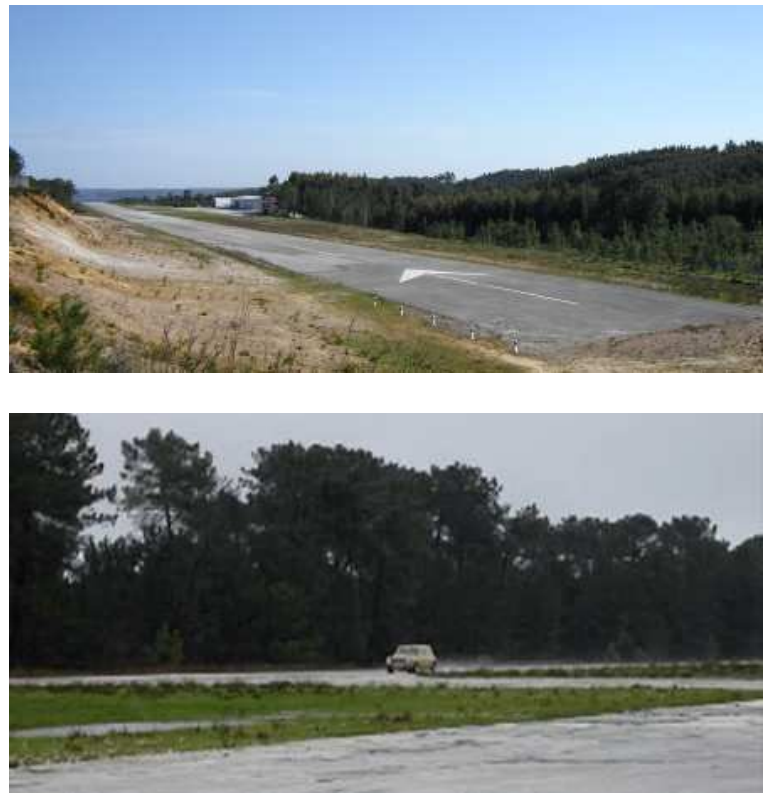

Fig. 6. Experimental tests to estimate the rolling resistance and aerodynamic drag coefficients.

Observing equations (5) and (6) could be concluded that the sum of rolling and aerodynamic resistance forces varies approximately in a quadratic way of the vehicle velocity.

$$
F_{R R}+F_{D A}=f_{r} \cdot m \cdot g+\frac{1}{2} \cdot \rho \cdot C_{D} \cdot A_{f} \cdot V_{V}^{2}
$$

To simplify equation (7) two parameters, $K_{l}$ and $K_{2}$, are considered.

$$
F_{R R}+F_{D A}=K_{1}+K_{2} \cdot V_{V}^{2}
$$

For the estimation of the forces $F_{R R}$ and $F_{D A}$ it was used an internal combustion vehicle (ICV), Mini 1000 similar to the developed VE. During each test the ICV was accelerated until a constant velocity and then disengaged. In this situation there isn't any traction or breaking forces applied to the vehicle, witch implies the following equation of the movement:

$$
\begin{aligned}
& F_{T}-F_{R T}=m \cdot a \Leftrightarrow \\
& \Leftrightarrow 0-K_{1}-K_{2} \cdot V_{V}^{2}=m \frac{d V_{V}}{d t}
\end{aligned}
$$

Solving the differential equation (9) results:

$$
\Delta t=\frac{m}{K_{2} \cdot \sqrt{K_{1} / K_{2}}} \cdot \operatorname{arctg}\left(\frac{V_{0}}{\sqrt{K_{1} / K_{2}}}\right)
$$

Where:

$$
\begin{aligned}
& V_{O} \text { - Initial velocity (before disengage) } \\
& \Delta t \text { - Time between disengage and the vehicle } \\
& \text { immobilization }
\end{aligned}
$$

This proceeding was made with several initial velocities $\left(V_{O}\right)$. The parameters $K_{l}$ and $K_{2}$ were estimated using the curve fitting tool from MATLAB, Fig. 7.

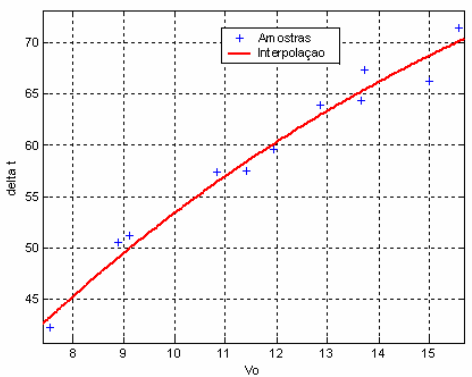

Fig. 7. Nonlinear interpolation of $K_{l}$ and $K_{2}$ parameters.

The rolling resistance and aerodynamic drag can be fitted by the following nonlinear interpolation.

$$
F_{R R}+F_{D A}=80,79+0,58 V_{V}^{2}
$$

\section{2) Traction forces}

The aim of this section is the dimensioning of the gearbox that couples the electrical machines to the wheels. Its purpose is to adapt the motor torque to overcome all resistant forces and accelerate the vehicle when necessary.

Considering the transmission ratio of the reduction gearbox, $r$, the angular velocities of the motor, $\omega_{m}$, and wheel, $\omega_{w}$, the following relations can be defined:

$$
\begin{gathered}
\omega_{w}=\frac{\omega_{m}}{r} \\
T_{w}=T_{m} \cdot r \cdot \eta_{t}
\end{gathered}
$$

Where $T_{m}$ and $T_{w}$ are the torque produced by the motor and wheel respectively, and $\eta_{t}$ is the transmission gearbox efficiency.

The gearbox allows the coupling of each motor to the respective wheel. The motors are fixed in the structure of the gearbox, Fig. 8.
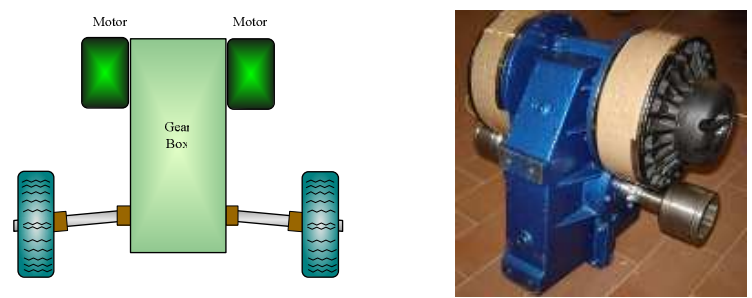

Fig. 8. Electric motors and gearbox. 
The transmission ratio of the reduction gearbox is a commitment between gradeability and maximum velocity [5]. The gearbox reduction ratio adopted was $r=4$, implying that, theoretically, based on the characteristics of the motors (referred in the next section) the vehicle can ride slopes up to $22 \%$ and reach $45 \mathrm{~km} / \mathrm{h}$. Fig. 9 represents the adaptation of the gearbox to the vehicle.

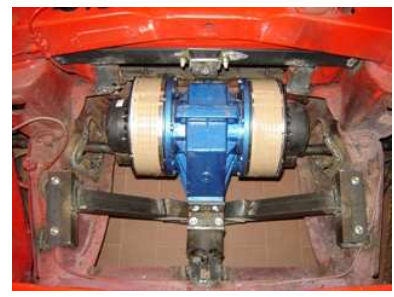

Fig. 9. Mechanical adaptation of the gearbox transmission to the chassis.

\section{Electric system of the vehicle}

The electric system of the vehicle, composed by batteries, motors, power converters, protections and filters, are represented in Fig. 10.
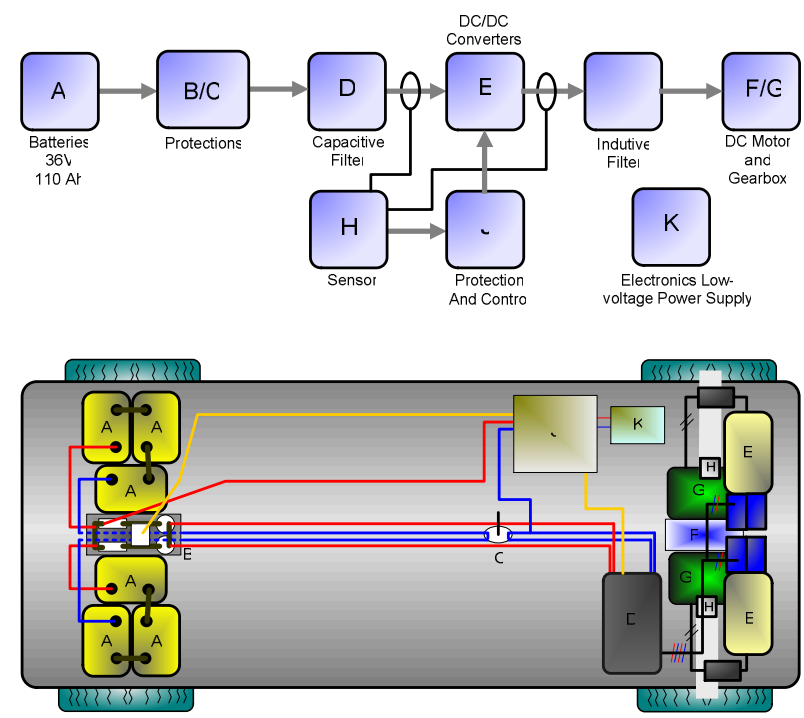

Fig. 10. Electric components of the vehicle.

The energy stored in the batteries, A, flows to the power converters, E, when the vehicle is accelerating or at constant velocity. During the regenerative breaking the electric machines, G, generate energy and charge the batteries. The protection, $\mathrm{B} / \mathrm{C}$, composed by power contactors and fuses ensures the safety of the equipment and passengers. The capacity filter, D, avoids overvoltages and stabilize the voltage at the power converter. The DC/DC power converter, E, is controlled and protected with electronic elements, J. The feedback signal is obtained by the Hall Effect sensor, H. The inductive filter, I, has the objective to attenuate the high frequency components of the current that flows to the electric motors.
In the next section the different blocks will analysed, with exception of the control and the inductive filter that will be focused in a different work.

\section{A. Electric Machines}

The used electric machines are of DC permanent magnet type, produced by LMC, Lynch Motor Company.

The table II specifies the motor characteristics for $36 \mathrm{~V}$ power supply. For this particular voltage the electromechanical characteristics are represented in Fig. 11.

Table II. - Motor Characteristics

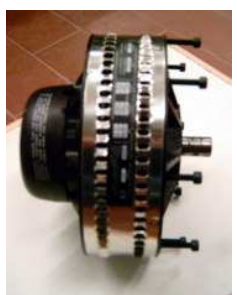

Voltage (V) 36

Max. Current (A)

Max. Power $(\mathrm{kW})$

Rotational speed (RPM)

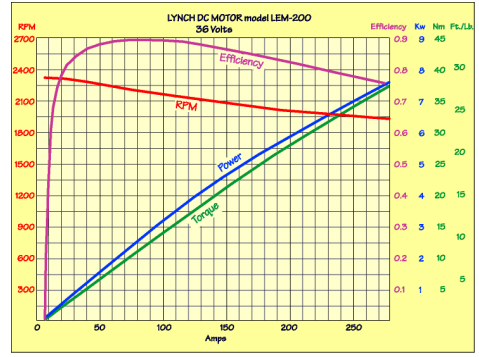

Fig. 11. Characteristic curves of the electric motors.

\section{B. Batteries}

The batteries used on the vehicle are Optima Yellow Top, model D34. They are specific for electric traction due to their robustness to deep discharges and long life cycle.

To achieved $36 \mathrm{~V}$ three batteries are needed in a series connection. To extend the vehicle autonomy two of these groups are used, which results in 110 Ah capacity.
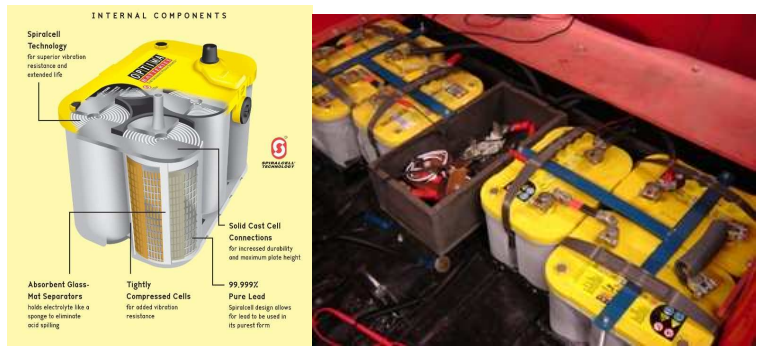

Fig. 12. Optima batteries and their association. 


\section{Electronic DC/DC Power Converter}

The topology for the DC-DC power converter is the full-bridge (Fig. 13).

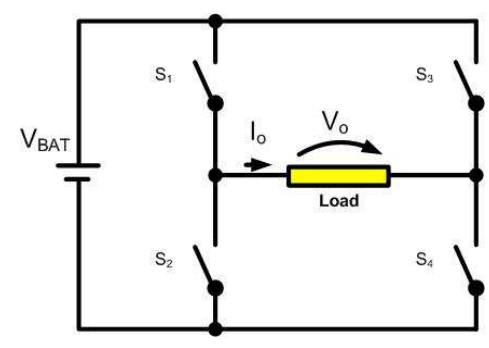

Fig. 13. Bridge DC/DC converter topology.

Each switch is implemented with 10 paralleled MOSFET transistors.

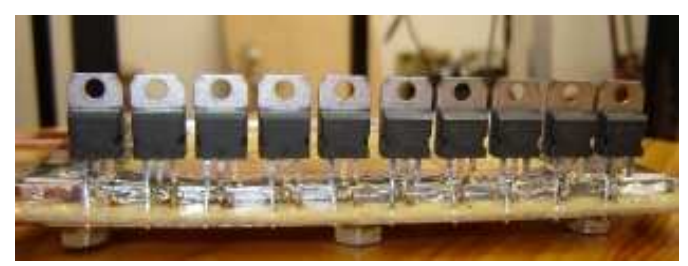

Fig. 14. One switch realization.

The objective of this solution is to create a low cost converter by the avoidance of specific high current transistors. The currents involved (almost 200A), the low resistance of the MOSFET (comparable to the ones of the conductors), and the parasitic inductances, obligates the transistors to be symmetrically coupled. This means that the current has to pass through approximately the same conductors length, independent of the transistor considered (to allow a harmonized distribution of the currents in the bridge), Fig. 15.

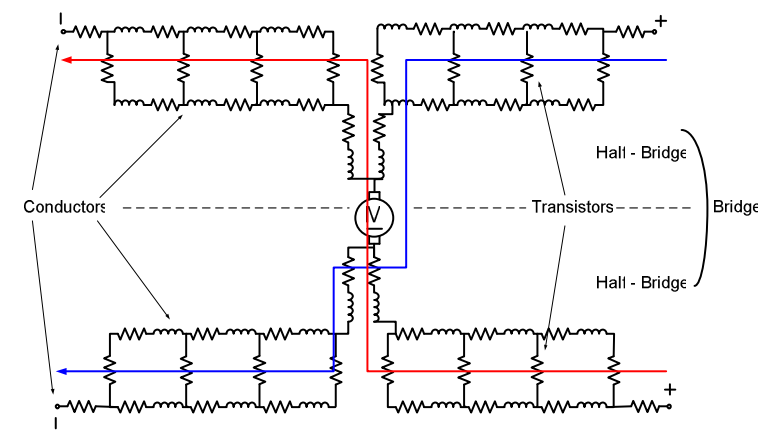

Fig. 15. Equivalent circuit used to guarantee a harmonized distribution of the current between transistors.

The converter implementation introduces parasitic inductances and resistances. Consequently some negative effects appear: transient voltages in the drain to source voltage of the transistors. Physically isn't possible to place all the sources terminal of the transistors connected to the same point. Consequently the $\mathrm{V}_{\mathrm{GS}}$ voltage present in different transistors will be dependent of their bus position, current and bus resistance, Fig. 16. In the figure, $\mathrm{V}_{\mathrm{GS}}$, represents the square wave produced by the drive circuit
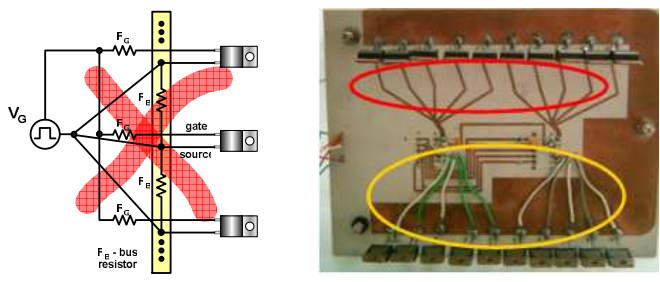

Fig. 16. Incorrect connection of the sources.

To minimize this effect, series source resistors are added, as represented in Fig. 17. This solution also minimizes the motor current that passes through the source connection conductors (which effectively were in parallel with the power buses conductors).
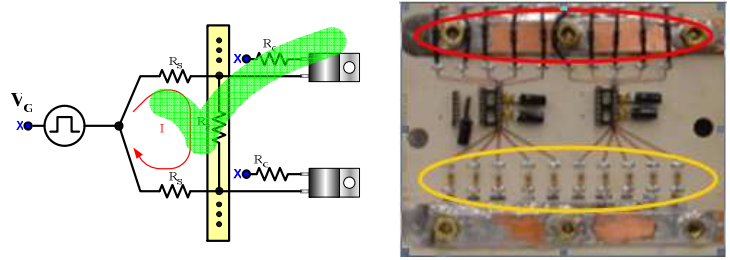

Fig. 17. Correct connection of sources terminal.

To avoid $\mathrm{V}_{\mathrm{DS}}$ overvoltages it was also necessary the addition of a capacitive filter in parallel with the converter. The parasitic inductances, $\mathrm{L}_{\mathrm{P}}$, were minimized by the addiction of metal plates in parallel with the conductors of the converter and with overvoltages snubbers as showed in the Fig. 18. [6] [7].

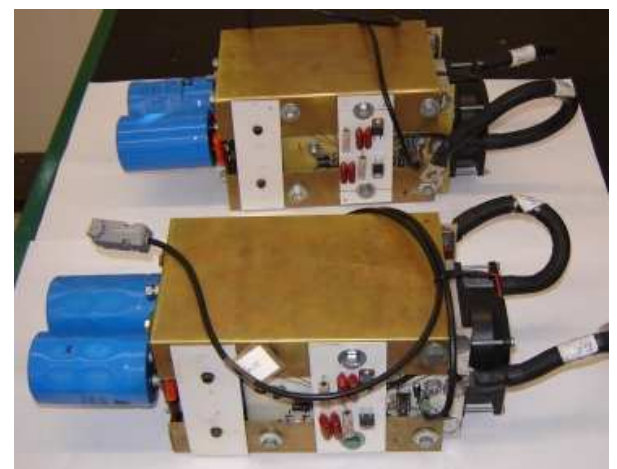

Fig. 18. Converter with metal plates.

\section{Snubbers}

During the first tests to the converters, made with low voltage, overvoltages at the transistors terminals appeared due to parasitic inductances. To solve this problem there were projected a suppress peaks circuit, usually called snubbers. The configuration adopted was overvoltage, represented on Fig. 19. 


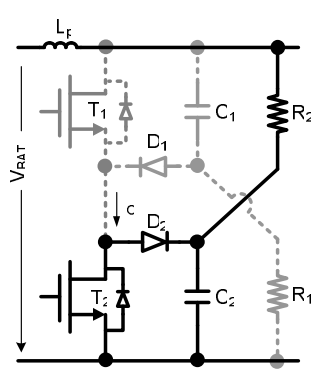

Fig. 19. Overvoltage Snubber.

During the transistors commutations, energy is stored in parasitic inductances. When the transistors turn off, that energy produces an overvoltage transient that depends of the circuit impedance.

Taking as example the transistor $\mathrm{T}_{2}$ snubber (formed by $\mathrm{C}_{2}, \mathrm{R}_{2}$ and $\mathrm{D}_{2}$ ), the principle of operation is: during $\mathrm{T}_{2}$ conduction time, the capacitors voltage is $\mathrm{V}_{\mathrm{BAT}}$, guaranteed by the resistor $R_{2}$; when $T_{2}$ open, if the drain-source voltage in $T_{2}$ is greater than $V_{B A T}, D_{2}$ conduces. The overvoltage obtained in $\mathrm{C}_{2}$ will be dependent of the stored energy into the parasitic inductance and of the capacitor value.

The dimensioning of the overvoltage snubber requires the measuring of the overvoltage value present without snubber, defined as a percentage of $\mathrm{V}_{\mathrm{BAT}}, \mathrm{kV}_{\mathrm{BAT}}$. In the present case the measured value was $\mathrm{kV}_{\mathrm{BAT}}=39 \mathrm{~V}$. The maximum admissible transistor drain to source overvoltage, $\mathrm{kV}^{\text {' }}{ }_{\mathrm{BAT}}$, also needs to be defined. In this case it was considered to be $24 \mathrm{~V}$. Fig. 20 shows the drain to source voltage without and with snubber.

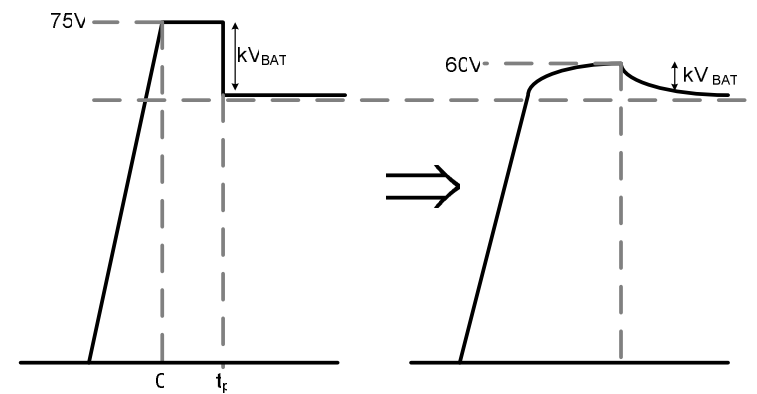

Fig. 20. Drain to source voltage on the transistor, without and with snubber.

An approximate value for the $L_{P}$ parasitic inductance can be obtained by equation 13 , based on the drain to source overvoltage when the circuit operates without the snubber [7].

$$
\begin{aligned}
& \mathrm{kV}_{\mathrm{BAT}}=\frac{\mathrm{L}_{\mathrm{p}} \mathrm{I} O}{\mathrm{t}_{\mathrm{p}}} \Leftrightarrow \mathrm{L}_{\mathrm{p}}=\frac{\mathrm{kV}_{\mathrm{BAT}} \mathrm{t}}{\mathrm{I}_{\mathrm{O}}} \Leftrightarrow \\
& \Leftrightarrow \mathrm{L}_{\mathrm{p}}=\frac{(75-36) \cdot 30 \cdot 10^{-9}}{50}=23,4 \mathrm{nH}
\end{aligned}
$$

The value of $C_{2}$ is given by the equation (14), [7]:

$$
\mathrm{C}_{2} \cdot \mathrm{kV}_{\mathrm{BAT}^{\prime}}{ }^{2}=\mathrm{L}_{\mathrm{p}} \cdot \mathrm{I}_{\mathrm{O}}^{2}
$$

The $\mathrm{C}_{2}$ value is:

$$
\mathrm{C}_{2}=\frac{\mathrm{L}_{\mathrm{p}} \cdot \mathrm{I}^{2}{ }_{\mathrm{O}}}{\mathrm{kV}_{\text {BAT }^{\prime}}{ }^{2}}=\frac{24 \times 10^{-9} \cdot 150^{2}}{(60-36)^{2}}=937,5 \mathrm{nF}
$$

According to the value obtained for $\mathrm{C}_{2}$, we adopted $\mathrm{C}_{2}=1 \mathrm{uF}$. A simulation of the snubber circuit allows obtaining the $\mathrm{R}_{2}$ value and their power dissipation. Fig. 21 shows the voltage on the $\mathrm{C}_{2}$ capacitor and the power dissipation in $R_{2}$, when $R_{2}=10 \Omega$ is considered (value required to discharge $C_{2}$ to $36 \mathrm{~V}$ during a switching frequency period of approx. $55 \mu \mathrm{s}$ ).

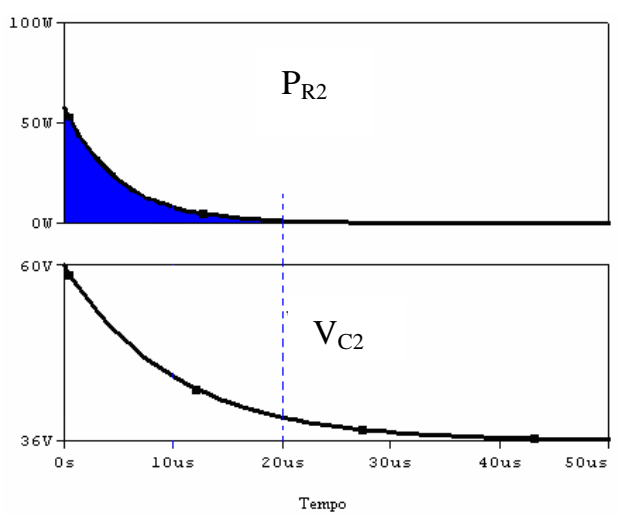

Fig. 21. Power in $\mathrm{R}_{2}$ and voltage in $\mathrm{C}_{2}, \mathrm{~V}_{\mathrm{C} 2}$, (simulation results).

Considering a linear approximation of the power dissipation curve, the average power in $\mathrm{R}_{2}$ is given by:

$$
\mathrm{P}_{\mathrm{R} 2}=\frac{\mathrm{t} \cdot \mathrm{P}_{\max } \cdot \mathrm{f}}{2}=\frac{20 \times 10^{-6} \cdot 50 \cdot 18 \cdot 10^{3}}{2}=9 \mathrm{~W}
$$

\section{E. Capacitor Batteries}

To prevent electromagnetic compatibility problems the converters are located as near as possible to the motors.

The batteries are located on the rear side of the vehicle; therefore, the cables to connect the converters to batteries are relatively long, $2,5 \mathrm{~m}$. The cables have a large section, $50 \mathrm{~mm}^{2}$, but they introduce a significant parasitic inductance between the converters and the batteries. To avoid overvoltages in the converter buses, caused by those inductances, large electrolytic capacitors are required. In our prototype we provide two capacitor array; one of $0,23 \mathrm{~F}$, shared by the two converters; and one array of $20.000 \mathrm{uF}$ in each converter. The ones are connected near the converter buses, in parallel with other MKT capacitors with a low Equivalent Series Resistance (ESR) and low Equivalent 
Series Inductance (ESL). The use of the MKT capacitors performs a better frequency response of the capacitors array. Fig. 22, shows the typical impedance variation of electrolytic and MKT capacitors with frequency.

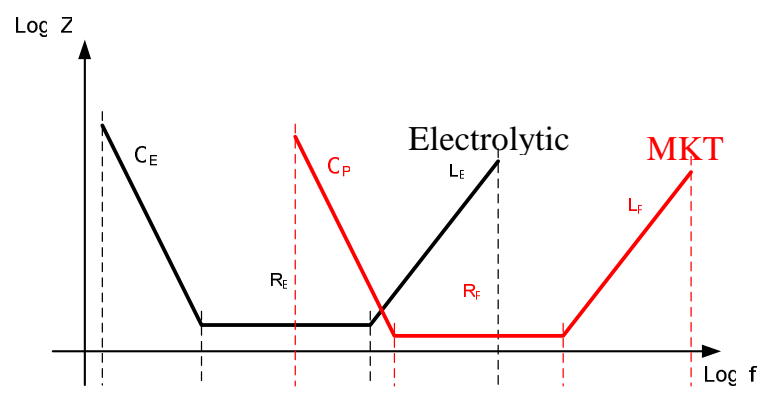

Fig. 22. Equivalent impedance of electrolytic and MKT capacitors.

Fig. 23 represents the physic mounting of the $20.000 \mu \mathrm{F}$ and $2,7 \mu \mathrm{F}$ MKT capacitors in the buses of the DC-DC converter and the $0,23 \mathrm{~F}$ array.

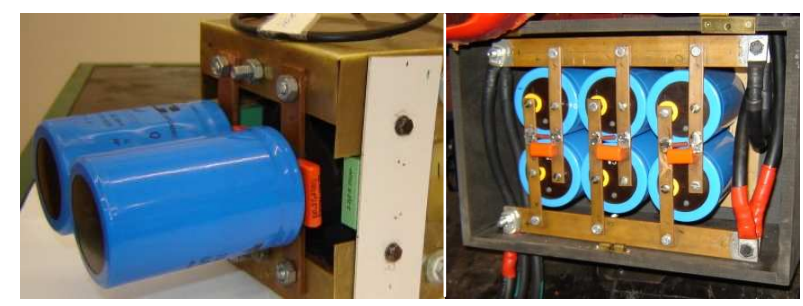

Fig. 23. Filter capacitors application (left), and 0,23F capacitors array (right).

\section{F. Protections}

To guarantee safety operation of the electric vehicle, (equipment and people safety) is necessary to attend the limits for the electric current.

Several protections have been made: emergency button, over current protection and undesirable starting.

Emergency button: when pressed the power supply is interrupted by a main contactor.

Over current protection: To guarantee the safety of the electric system an over current protection was made. It is based on a signal produced by a Hall Effect sensor (LEM 200) that measures the input current of each converter. When the maximum value is reached (200A) this circuit will turn off all the converter transistors. Fig. 24 represents the schematic of the circuit used.

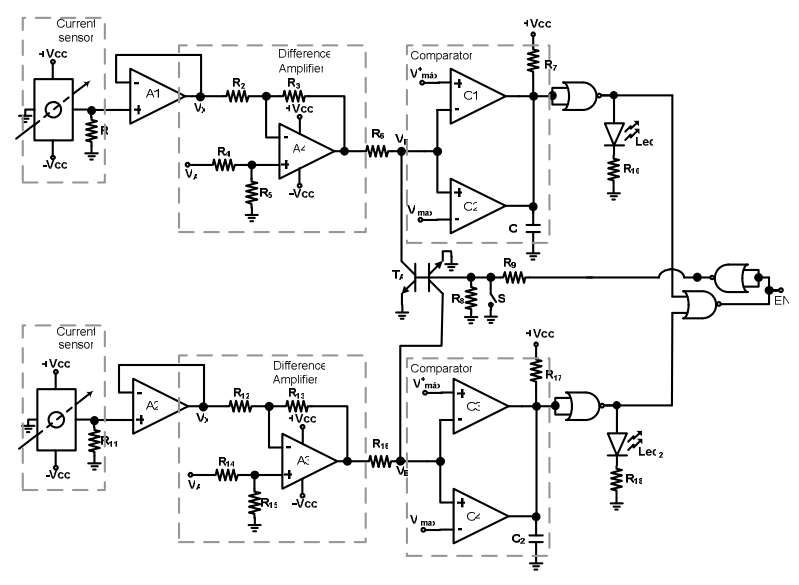

Fig. 24. Overcurrent protection circuit.

Undesirable starting: this protection inhibits the system to turn on when the throttle control is pressed, avoiding unexpected and accidental abrupt starts. This also avoids the system to start if the DC/DC converter is damaged. Fig. 25 represents a simplification of the circuit used.

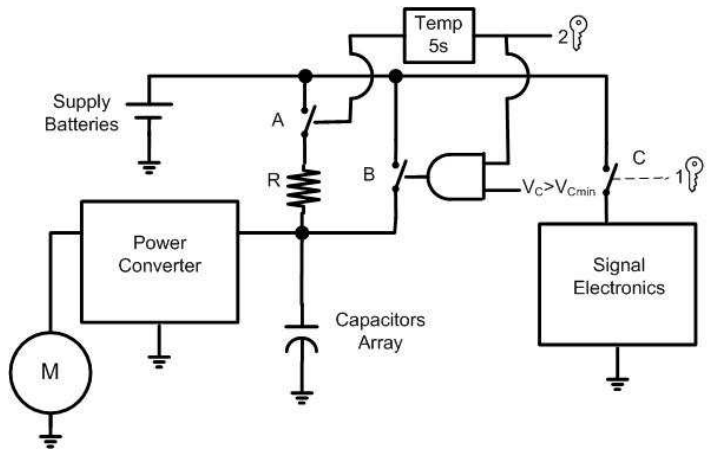

Fig. 25. Simplified scheme of the undesirable starting system.

The system operation could bee divided in tree phases:

First phase: The relay $\mathrm{C}$ is turned-on with the first position of the switch key, the low power electronics is then connected to the supply voltage.

Second phase: When turning the key to the second switch position, the relay $\mathrm{A}$ is supplied with power by a $5 \mathrm{~s}$ timer (this is the time needed to charge the capacitors array by the resistor $\mathrm{R}$ ).

Third phase: If in the 5 seconds provided by the timer the capacitors array voltage reaches the minimum value, $\mathrm{V}_{\mathrm{Cmin}}$, this means that the throttle control isn't pressed and everything is correct. Then the solenoid of the relay $\mathrm{B}$ is turned on and the power contactor B connects the batteries to the power converters. If the throttle control is pressed, the current absorbed by the DC/DC power converter don't allows the capacitors array voltage to reach the minimum value $\mathrm{V}_{\mathrm{Cmin}}$ in the $5 \mathrm{~s}$ interval and the system do not connect power contactor $\mathrm{B}$. 
Fig. 26 represents the total implementation circuit.

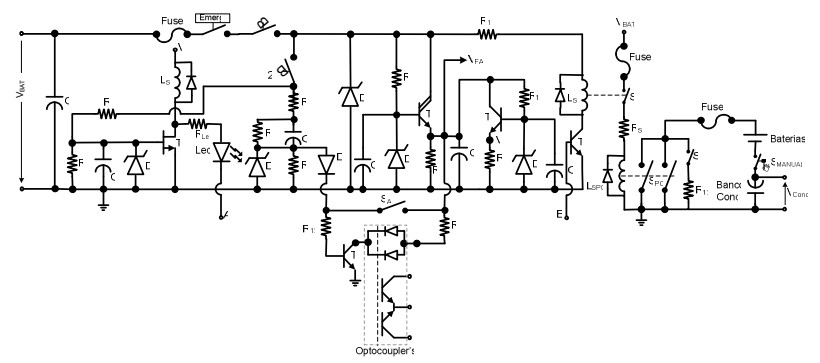

Fig. 26. Undesirable starting protection circuit.

\section{Tests}

Fig. 27 shows the output voltage and current waveforms of the power converter. For this measure a differential pair of probes and a current sensor has been used.

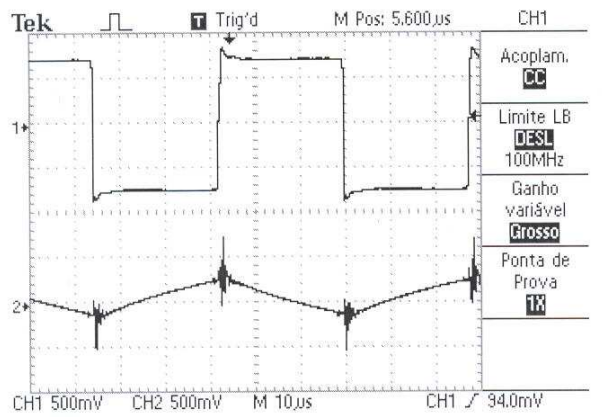

Fig. 27. Voltage and current waveforms in the power converters (CH1:25V/div, $\mathrm{CH} 2: 25 \mathrm{~A} / \mathrm{div})$.

Fig. 28 represents a test of the over current protection. With an applied duty cycle of $30 \%$, the mechanic brakes of the vehicle were gradually pressed. The current increases to a maximum value of approximate 200A; at that moment the protection system actuates, the power converters were shutdown and the current becomes zero.

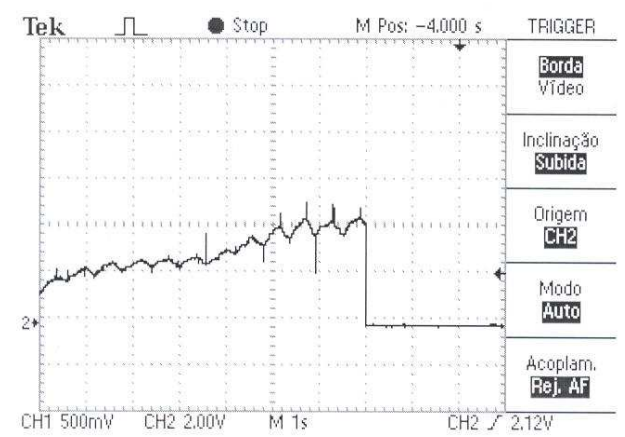

Fig. 28. Over current protection test (100A/div).

Fig. 29 represents the electronic system mounted in the vehicle.

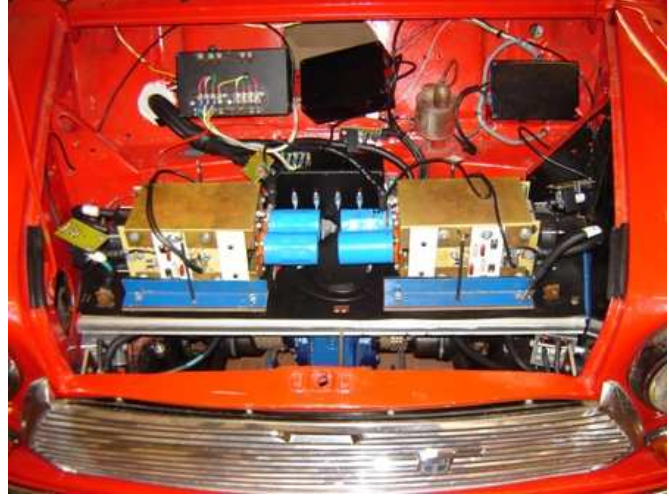

Fig. 29. Electronic system mounted in the vehicle.

\section{Conclusions}

The present paper focus several problems related with the electrical traction implementation on a vehicle. There were dimensioned the components of the power train chain, with the purpose that the vehicle could satisfy the gradability and maximum velocity constrictions.

The DC/DC power converter uses 10 MOSFET transistor's in parallel for each switch, this solution lowers the cost of the system. Special layout techniques are used to assure equal distribution of currents by the several transistors. For the purpose of attaining a secure system, several potential danger situations were identified and solutions were presented.

\section{References}

[1] Granchinho de Matos, Pedro Manuel - Modelos e optimização energética de veículos eléctricos, Dissertação de mestrado - IST Lisboa, Julho de 2005

[2] Roque, António Eusébio Velho - Contributos para um controlo de tracção de um veículo eléctrico bimotor, Dissertação de mestrado - IST Lisboa Julho de 2001

[3] Genta G., "Motor Vehicle Dynamics - Modelling and Simulation" World Scientific, ISBN 981-022911-9, 1997.

[4] Gillespie, T., "Fundamentals of Vehicle Dynamics", Society of Automotive Engineers, ISBN 1-56091-199-9, 1992.

[5] Palma, João C. P. - Accionamentos Electromecatrónicos de Velocidade Variável Fundação Calouste Gulbenkian, 1999

[6] Bose, Bimal K. - Power electronics and variable frequency drives - IEEE press, 1996

[7] Mohan Ned, Undeland Tore, Robbins William Power Electronics Converters, Applications, and Design - John Wley \& Sons, INC 